\title{
The influence of nitrogen pressure on the fabrication of the two-phase superhard nanocomposite (TiZrNbAlYCr)N coatings
} \author{
G.G. Bondarenko ${ }^{\mathrm{d}}$ \\ a Sumy State University, 40007, Rymskogo-Korsakova st. 2, Sumy, Ukraine \\ ${ }^{\mathrm{b}}$ V.N. Karazin Kharkiv National University, 61022, Svobody sq. 4, Kharkiv, Ukraine \\ ${ }^{\mathrm{c}}$ Lublin University of Technology, 20-001, Nadbystrzycka st. 38D, Lublin, Poland \\ ${ }^{\mathrm{d}}$ National Research University, Higher School of Economics, 101000, Myasnitskaya st. 20, Moscow, Russia
}

A.D. Pogrebnjak ${ }^{a, *}$, V.M. Beresnev ${ }^{b}$, K.V. Smyrnova ${ }^{a}$, Ya.O. Kravchenko ${ }^{a}$, P.V. Zukowski ${ }^{c}$,

\section{A R T I C L E I N F O}

\section{Article history:}

Received 29 August 2017

Received in revised form 26 September

2017

Accepted 30 September 2017

Available online 3 October 2017

\section{Keywords:}

Microstructure

Multielement

Chemical composition

Superhardness

Crystallites

\begin{abstract}
A B S T R A C T
The multicomponent nitride coatings from TiZrNbAlYCr high entropy alloy (HEA) were fabricated using the vacuum-arc method. The effect of nitrogen pressure on the crystallite size, elemental and phase composition of (TiZrNbAlYCr)N coatings was investigated. A bias voltage applied to the substrate during the deposition process was $-200 \mathrm{~V}$. The partial nitrogen pressure was $0.05 \mathrm{~Pa}, 0.27 \mathrm{~Pa}$, and $0.5 \mathrm{~Pa}$. Bodycentered cubic (BCC) lattice with crystallites of $15 \mathrm{~nm}$ in size was formed at the lowest pressure. An increase in the pressure led to the formation of the two-phase structure: BCC phase with crystallite size of $15 \mathrm{~nm}$ and face-centered cubic (FCC) phase with crystallite size of about $3.5 \mathrm{~nm}$. The same two-phase state was found in coatings fabricated at $0.5 \mathrm{~Pa}$, while the mean crystallite size was $7 \mathrm{~nm}$. The maximum hardness of the deposited coatings was about $47 \mathrm{GPa}$.
\end{abstract}

(C) 2017 Elsevier B.V. All rights reserved.

\section{Introduction}

The high-entropy alloys (HEAs) consisting of more than five elements of transition and refractory metals are widely applied materials nowadays. They can be used to solve the fundamental and applied problems, such as fabricating coatings, studying their structure and properties, or using the products covered with these coatings in practice [1-5]. The nitrides and carbides from HEAs significantly improve the characteristics of materials: radiation, wear, and corrosion resistance. Many different HEAs have been fabricated and investigated; however, the coatings based on such alloys do not always possess excellent physicalmechanical properties [6-9]. Fabrication of nitride coatings from high-entropy alloys with high hardness, oxidation resistance, and thermal stability is an issue of current interest. Thus, new coatings based on TiZrNbAlYCr HEA were deposited using vacuumarc evaporation of a cathode, their structure and properties were described.

\footnotetext{
* Corresponding author.

E-mail address: alexp@i.ua (A.D. Pogrebnjak).
}

\section{Experimental details}

The multicomponent (TiZrNbAlYCr)N coatings were deposited on the stainless-steel substrates via the vacuum-arc method using Bulat- 6 setup. The basic pressure in the vacuum chamber was $1.3 \times 10^{-3} \mathrm{~Pa}$. A partial nitrogen pressure was $0.05 \mathrm{~Pa}, 0.27 \mathrm{~Pa}$, and $0.5 \mathrm{~Pa}$ for different series of samples, the accuracy of the pressure control was $10-15 \%$. A constant bias potential, $U_{b}$, applied to the substrate was $-200 \mathrm{~V}$. The deposition temperature was about $300-350{ }^{\circ} \mathrm{C}$, and the substrate-to-arc evaporator distance was equal to $200 \mathrm{~mm}$. Coatings were deposited using non-filtered plasma flow, arc current was $100 \mathrm{~A}$, and focusing coil current was $0.5 \mathrm{~A}$. A complex cathode sintered on a spark plasma sintering SPS 25-10 device had the following composition: Ti-25 at.\%; Zr-20 at.\%; Nb-20 at.\%; Cr-25 at.\%; Al-7 at.\%; Y 3 at.\%. Samples with the total thickness of $7.0 \mu \mathrm{m}$ were deposited during $1 \mathrm{~h}$, deposition rate was $0.12 \mu \mathrm{m} / \mathrm{min}$.

The phase composition of coatings was investigated by X-ray diffraction analysis using X'Pert PANanalytical system with filtered $\mathrm{Cu}-\mathrm{K} \alpha$ radiation (1.54 $\AA$ ) according to the Bragg-Brentano scheme. 2Theta range varied from 30 to 75 degree with a step duration of 0.05 degree. Deconvolution of the complex X-ray diffraction profiles into components was performed by means of "HighScore Plus" software package. The elemental composition and cross sections of 

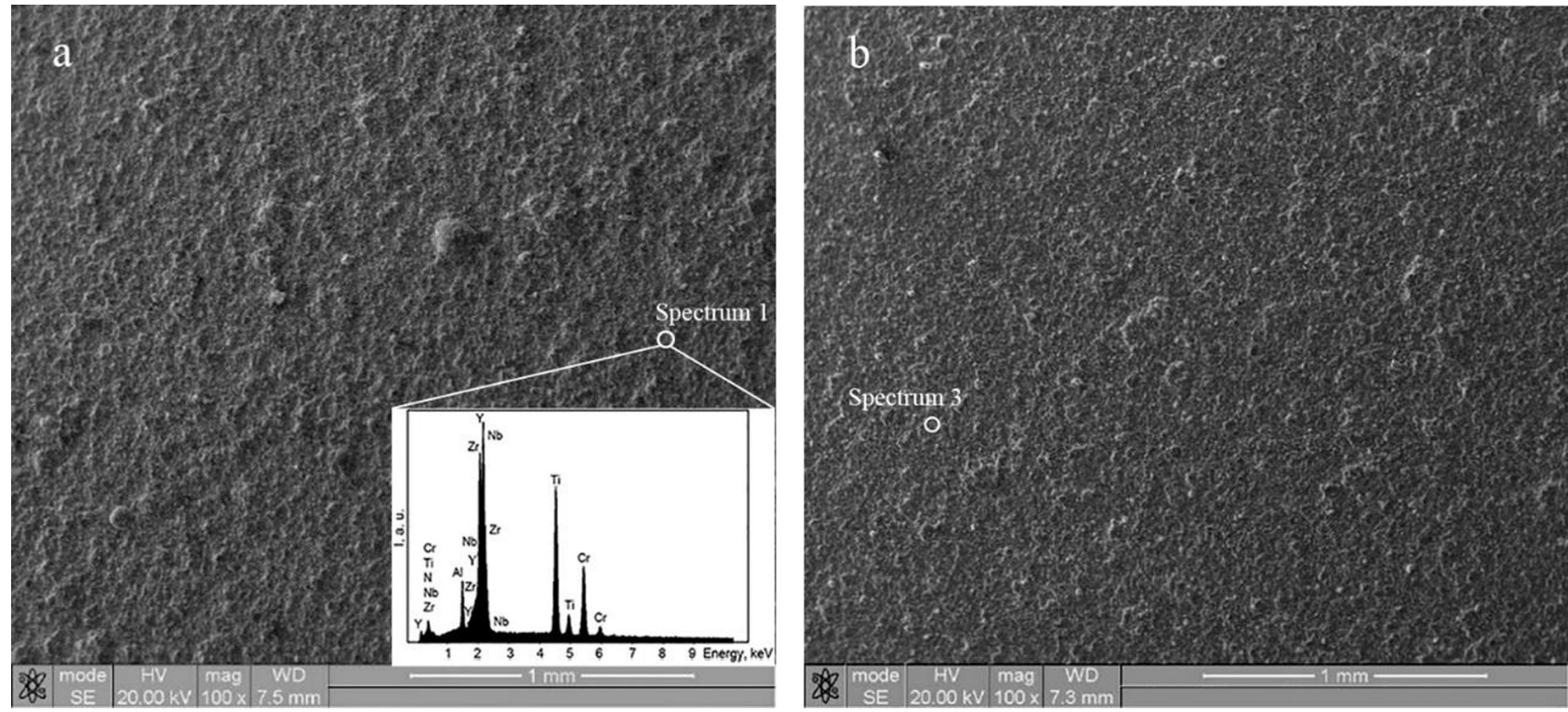

Fig. 1. SEM images of the surface morphology with EDS pattern of (TiZrNbAlYCr)N coatings deposited at (a) $0.05 \mathrm{~Pa}$ and (b) $0.5 \mathrm{~Pa}$.

Table 1

The elemental composition of (TiZrNbAlYCr)N coatings fabricated at different partial pressures of nitrogen.

\begin{tabular}{|c|c|c|c|c|c|c|}
\hline \multirow[t]{2}{*}{ Element } & \multicolumn{2}{|c|}{$0.05 \mathrm{~Pa}$} & \multicolumn{2}{|c|}{$0.27 \mathrm{~Pa}$} & \multicolumn{2}{|l|}{$0.5 \mathrm{~Pa}$} \\
\hline & wt.\% & at.\% & wt.\% & at.\% & wt.\% & at.\% \\
\hline $\mathrm{N}$ & 2 & 9 & 1 & 2 & 5 & 22 \\
\hline $\mathrm{Al}$ & 2 & 5 & 2 & 5 & 4 & 7 \\
\hline Y & 4.3 & 2.9 & 4.3 & 3.3 & 4.4 & 2.5 \\
\hline $\mathrm{Zr}$ & 24.3 & 16.2 & 26.0 & 18.8 & 22.8 & 14.0 \\
\hline $\mathrm{Nb}$ & 27.5 & 18.0 & 28.8 & 20.5 & 23.8 & 14.2 \\
\hline $\mathrm{Ti}$ & 21.8 & 27.7 & 19.7 & 27.2 & 21.2 & 25.0 \\
\hline $\mathrm{Cr}$ & 18.1 & 21.2 & 18.2 & 23.2 & 18.8 & 15.3 \\
\hline Total & 100.0 & 100.0 & 100.0 & 100.0 & 100.0 & 100.0 \\
\hline
\end{tabular}

coatings were studied by scanning electron microscope JEM-7001 TTLS (JEOL) with EDS microprobe at SEI and Compo modes. The crystallite sizes were calculated using Scherrer equation (error in the determination is about $20 \%$ ). The microhardness was measured by the Vickers method using DM- 8 device at a load of $0.5 \mathrm{~N}$.

\section{Results and discussion}

SEM images of the surface morphology with EDS pattern (Fig. 1) show changes stimulated by an increase in the partial nitrogen pressure. The reduction in the mean size of droplet fractions on the coating surface was observed with an increase in partial nitrogen pressure. Another reason is the appearance of cathode spots of the first type. They have much lower erosion coefficient, and particles return to the cathode faster due to the collisions with atoms and molecules of the gas. Formation of the refractory compounds with higher melting points (such as TiN) on the cathode surface leads to decrease in the size and number of droplet fractions [10].

Elemental composition of the samples is presented in Table 1. The accuracy of EDS corresponds to $0.1-1 \%$. An increase in the nitrogen pressure caused both saturation of the coatings with nitrogen atoms and rise of the content of light $\mathrm{Al}$ atoms.

Results of X-ray phase and structural analysis of (TiZrNbAlYCr) $\mathrm{N}$ coatings are shown in Fig. 2 . At the lowest nitrogen pressure, $P_{N}$ $=0.05 \mathrm{~Pa}$, we observe the BCC solid solution of metal atoms. The mean crystallite size was about $15 \mathrm{~nm}$ and the lattice parameter was $0.342 \mathrm{~nm}$. The profiles of diffraction spectrum corresponding

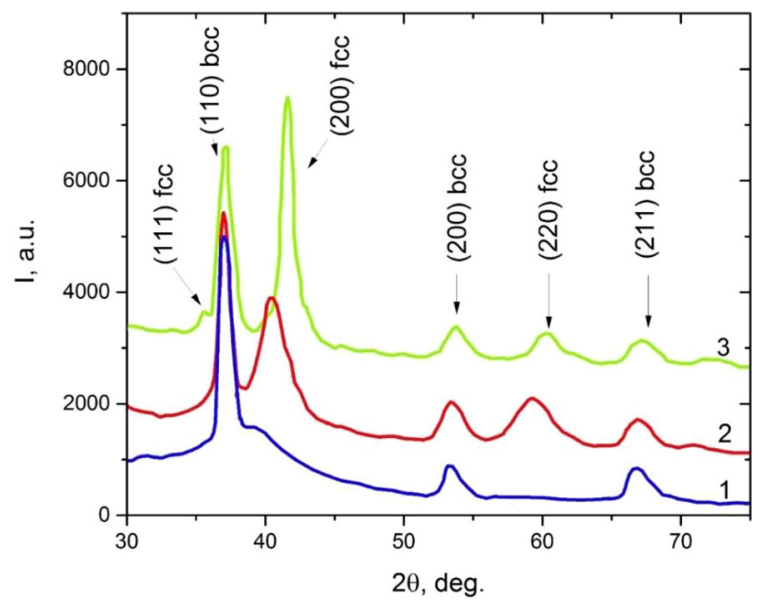

Fig. 2. Diffraction spectra of (TiZrNbAlYCr)N coatings fabricated at different pressures: 1 - 0.05 Pa, $2-0.27 \mathrm{~Pa}, 3-0.5 \mathrm{~Pa}$.

to coatings deposited at $0.05 \mathrm{~Pa}$ (Fig. 3a) indicate the presence of $2 \mathrm{~nm}$ nanocrystalline regions. It is confirmed by spectrum 1 in Fig. 2, where a broad halo-like peak appears at larger angles.

The analysis of the diffraction spectra of samples fabricated at $0.27 \mathrm{~Pa}$ (spectrum 2 in Fig. 2, Fig. 3b) demonstrates that the peak corresponding to the BCC phase is close to that considered earlier in the both position and width. The halo-like diffuse peak from 

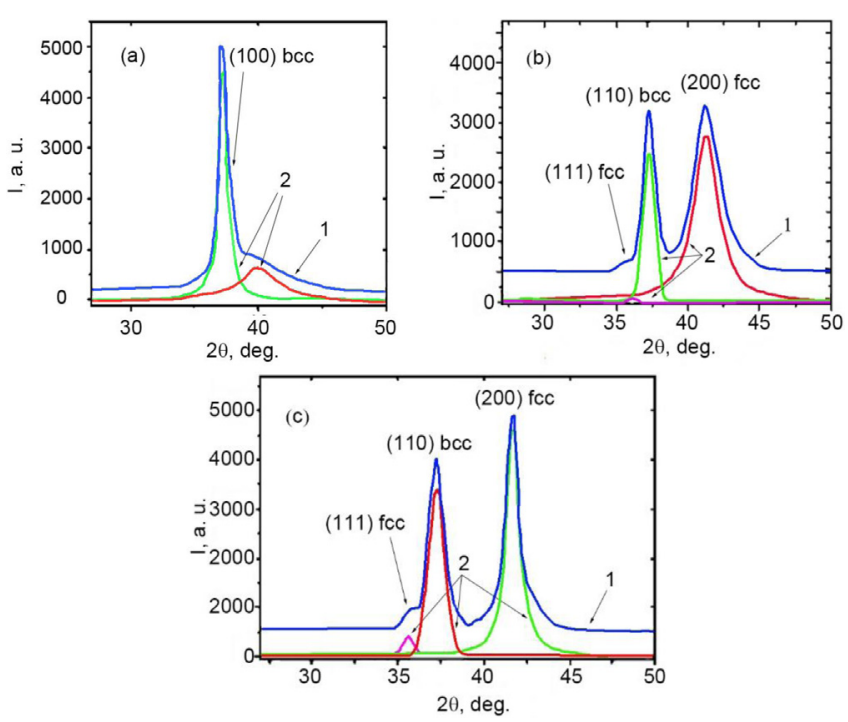

Fig. 3. Deconvolution of the complex X-ray diffraction profiles into components for (TiZrNbAlYCr)N coatings fabricated at different $P_{N}$ : (a) $-0.05 \mathrm{~Pa}$, (b) $-0.27 \mathrm{~Pa}$, (c) $0.5 \mathrm{~Pa} ; 1$ - initial spectrum, 2 - component profiles.

the second component profile is more ordered, but its position is shifted towards larger diffraction angles. The calculation of the coherent scattering region gives a value of about $3.5 \mathrm{~nm}$. A new peak emerged at 60 degrees in spectrum 2 (Fig. 2) corresponds to the presence of FCC nitride phase with $\mathrm{NaCl}$ [1111]-type structure.

The nitrogen content exceeds 21 at.\% in coatings fabricated at $P_{N}=0.5 \mathrm{~Pa}$ according to the Table 1 . X-ray diffraction results for this series of samples (spectrum 3 in Fig. 2, Fig. 3c) show the formation of two-phase structure, which contains BCC phase (lattice parameter is $0.342 \mathrm{~nm}$ ) and FCC phase of NaCl-type (lattice parameter is $0.437 \mathrm{~nm}$ ). The mean crystallite size in this case was about $7 \mathrm{~nm}$.

The peaks at larger angles (range from $52^{\circ}$ to $68^{\circ}$ ) of all X-ray spectra in Fig. 2 belong to the second FCC phase. The observed shift towards smaller angles (indicated by arrow in Fig. 2) and the blurring of the diffraction reflexes in coatings fabricated at lower nitrogen pressure can be associated with the formation of packing defects due to the displacement of the lattice planes with low nitrogen content. This phenomenon is caused by high-energy metal particles bombarding the coating at low pressure and the negative bias potential. In coatings, we observed both macroand microdeformation, which stimulated the formation of packing defects. They are induced by significant differences in sizes of HEA atoms. An increase of the working gas pressure in the deposition chamber led to decrease in the average energy of deposited particles (due to the collision losses in the interelectrode gap), reduction in the coating deformation, and increase in the saturation of coatings with nitrogen content. The nitrogen atoms formed the metallic chemical bonds and occupied octahedral interstitial sites, typical for NaCl-type lattice. As a result, they prevented the displacement of planes by the formation of packing defects. Such structural changes led to an increase in hardness of the coatings deposited at the highest nitrogen pressure, $P_{N}=0.5 \mathrm{~Pa}$.

The investigation of the microhardness of (TiZrNbAlYCr)N coatings by DM- 8 device (indentation load was $0.5 \mathrm{~N}$ ) showed the follow results. The Vickers hardness of samples deposited at $0.05 \mathrm{~Pa}$,
$0.27 \mathrm{~Pa}$, and $0.5 \mathrm{~Pa}$ was $35 \pm 1.4 \mathrm{GPa}, 42 \pm 1.8 \mathrm{GPa}$, and $47 \pm 2.3 \mathrm{G}$ $\mathrm{Pa}$, respectively. Thus, we can state that the deposited (TiZrNbAlYCr)N coatings are superhard ones.

\section{Conclusions}

(TiZrNbAlYCr)N multicomponent coatings were deposited using the vacuum-arc evaporation of the cathode on the stainless-steel substrates under different nitrogen pressure: $0.05 \mathrm{~Pa}, 0.27 \mathrm{~Pa}$, and $0.5 \mathrm{~Pa}$. The analysis of the deposited coatings demonstrated the following:

- The size of droplet fractions on the coating surface was decreased due to the rise of nitrogen pressure and the formation of the refractory compounds with higher melting points on the cathode surface;

- Saturation with nitrogen atoms and increase in the content of Al atoms were observed at higher pressure;

- Increase in the nitrogen pressure led to the transformation from monophase $(B C C)$ to two-phase $(B C C+F C C)$ structure; the reduction in the size of $\mathrm{BCC}$ crystallites and increase in the size of FCC crystallites; as well as the increase in hardness: $35 \mathrm{GPa}$, $42 \mathrm{GPa}$, and $47 \mathrm{GPa}$ at $0.05 \mathrm{~Pa}, 0.27 \mathrm{~Pa}$, and $0.5 \mathrm{~Pa}$, respectively. Therefore, coatings demonstrated a superhard state.

\section{Acknowledgements}

The authors are grateful to O.V. Sobol' for help in interpreting the results of X-ray analysis. This work was carried out under the financial support of the Ministry of Education and Science of Ukraine in the framework of the state program № 0115 U000682 "Development of material science fundamentals of structure engineering of vacuum-plasma superhard coatings with given functional properties".

\section{References}

[1] A.D. Pogrebnjak, A.A. Bagdasaryan, I.V. Yakushchenko, V.M. Beresnev, The structure and properties of high-entropy alloys and nitride coatings based on them, Rus. Chem. Rev. 83 (11) (2014) 1027-1061.

[2] D.B. Miracle, O.N. Senkov, A critical review of high entropy alloys and related concepts, Acta Mater. 122 (2017) 448-511.

[3] A.D. Pogrebnjak, I.V. Yakushchenko, O.V. Bondar, V.M. Beresnev, K. Oyoshi, O. M. Ivasishin, H. Amekura, Y. Takeda, M. Opielak, Cz. Kozak, Irradiation resistance, microstructure and mechanical properties of nanostructured (TiZrHfVNbTa)N coatings, J. Alloys Compd. 679 (2016) 155-163.

[4] A.D. Pogrebnjak, I.V. Yakushchenko, A.A. Bagdasaryan, O.V. Bondar, R. KrauseRehberg, G. Abadias, P. Chartier, K. Oyoshi, Y. Takeda, V.M. Beresnev, O.V. Sobol', Microstructure, physical and chemical properties of nanostructured (Ti-Hf-Zr-V-Nb)N coatings under different deposition conditions, Mater. Chem. Phys. 147 (2014) 1079-1091.

[5] V. Braic, A. Vladescu, M. Balaceanu, C.R. Luculescu, M. Braic, Nanostructured multi-element (TiZrNbHfTa)N and (TiZrNbHfTa)C hard coatings, Surf. Coat. Technol. 211 (2012) 117-121.

[6] A.D. Pogrebnjak, Structure and properties of nanostructured (Ti-Hf-Zr-V-Nb)N coatings, J. Nanomater. 2013 (2013) 1-12, I.D. 780125.

[7] Y. Zhang, T.T. Zuo, Z. Tang, M.C. Gao, K.A. Dahmenet, P.K. Liaw, Z.P. Lu, Microstructures and properties of high-entropy alloys, Prog. Mater. Sci. 61 (2014) 1-93.

[8] D.C. Tsai, Z.C. Chang, B.H. Kuo, M.H. Shiao, S.Y. Chang, F.S. Shieu, Structural morphology and characterization of (AlCrMoTaTi) N coating deposited via magnetron sputtering, Appl. Surf. Sci. 282 (2013) 789-797.

[9] M.H. Tsai, C.W. Wang, C.H. Lai, J.W. Yeh, J.Y. Gan, Thermally stable amorphous (AlMoNbSiTaTiVZr $)_{50} \mathrm{~N}_{50}$ nitride film as diffusion barrier in copper metallization, Appl. Phys. Lett. 92 (2008) 052129(1)-052129(3).

[10] S.K. Sethuraman, M.R. Barrault, Study of the motion of vacuum arcs in high magnetic field, J. Nucl. Mater. 93-94 (1980) 791-798. 